MICHAEL LAUSE, BS

The Ohio State University College

of Medicine, Columbus, $\mathrm{OH}$
ALISHA KAMBOJ, BS

The Ohio State University College of Medicine, Columbus, $\mathrm{OH}$
RYAN SCHWIETERMAN, MD

Department of Internal Medicine, Mercy Health St. Rita's Medical Center, Lima, $\mathrm{OH}$
VIJAY DUGGIRALA, MD

Department of Internal Medicine, The Ohio State University Wexner Medical Center, Columbus, $\mathrm{OH}$

\title{
Back pain as a sign of inferior vena cava filter complications
}

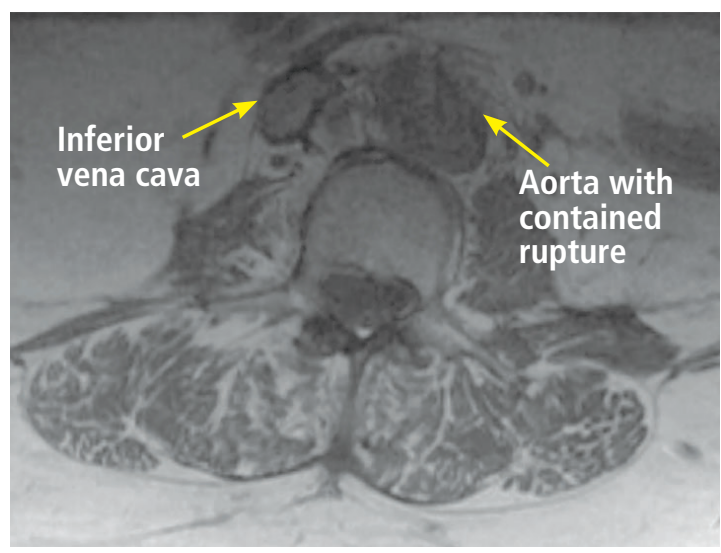

Figure 1. Magnetic resonance imaging of the lumbar spine showed a para-aortic heterogeneous collection, suspected of being a retroperitoneal hematoma.

\begin{abstract}
A 63-YEAR-OLD WOMAN presented with an acute exacerbation of chronic back pain after a fall. She was taking warfarin because of a history of factor V Leiden, deep vein thrombosis, and pulmonary embolism, for which a temporary inferior vena cava (IVC) filter had been placed 8 years ago. Her physicians had subsequently tried to remove the filter, without success. Some time after that, 1 of the filter struts had been removed after it migrated through her abdominal wall.

Laboratory testing revealed a supratherapeutic international normalized ratio of 8.5.

Magnetic resonance imaging of the lumbar spine showed a para-aortic heterogeneous collection, suspected of being a retroperitoneal hematoma (Figure 1).
\end{abstract}

Dr. Duggirala has disclosed a commercial interest as a consultant for EBSCO Health.

doi:10.3949/ccjm.85a.18046

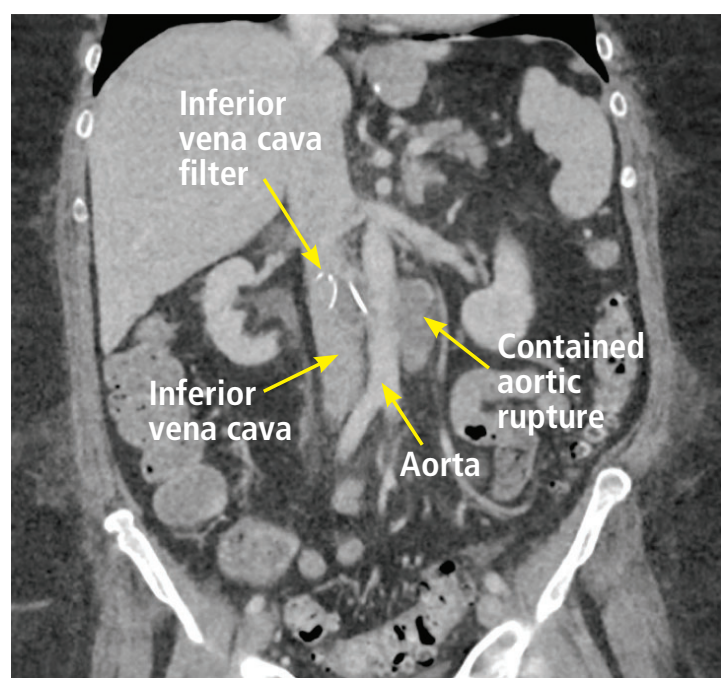

Figure 2. Computed tomographic angiography of the abdomen and pelvis revealed a contained aortic rupture and inferior vena cava filter struts within clotted blood adjacent to an aortic pseudoaneurysm.

Computed tomographic angiography of the abdomen and pelvis subsequently revealed a contained aortic rupture, a filter strut within clotted blood adjacent to an aortic pseudoaneurysm, and additional filter struts within the second portion of the duodenum and renal pelvis (Figure 2).

The patient underwent endovascular aneurysm repair with adequate placement of a vascular graft. She was discharged on therapeutic anticoagulation, and her back pain had notably improved.

\section{COMPLICATIONS OF IVC FILTERS}

In the United States, the use of IVC filters has increased significantly over the last decade,
$12 \%-17 \%$ of patients with venous thromboembolism now receive an IVC filter 
with placement rates ranging from $12 \%$ to $17 \%$ in patients with venous thromboembolism. ${ }^{1}$

The American Heart Association recommends filter placement for patients with venous thromboembolism for whom anticoagulation has failed or is contraindicated, patients unable to withstand pulmonary embolism, and patients who are hemodynamically unstable. ${ }^{2}$ While indications vary in the guidelines released by different societies, filters are most often placed in patients who have an acute bleed, significant surgery after admission for venous thromboembolism, metastatic cancer, and severe illness. ${ }^{3}$

Complications can occur during and after insertion and during removal. They are more frequent with temporary than with permanent filters, and include filter movement and fracture as well as occlusion and penetration.., 5

In our patient, we believe that the 3 re-

\section{REFERENCES}

1. Alkhouli M, Bashir R. Inferior vena cava filters in the United States: less is more. Int J Cardiol 2014; 177(3):742743. doi:10.1016/j.ijcard.2014.08.010

2. Jaff MR, McMurtry MS, Archer SL, et al; American Heart Association Council on Cardiopulmonary, Critical Care, Perioperative and Resuscitation; American Heart Association Council on Peripheral Vascular Disease; American Heart Association Council on Arteriosclerosis, Thrombosis and Vascular Biology. Management of massive and submassive pulmonary embolism, iliofemoral deep vein thrombosis, and chronic thromboembolic pulmonary hypertension: a scientific statement from the American Heart Association. Circulation 2011; 123(16):1788-1830. doi:10.1161/CIR.0b013e318214914f maining filter struts likely penetrated the wall of the IVC to the extent that they encountered adjacent structures (aorta, duodenum, kidney).

Of cases of IVC filter penetration reported to a US Food and Drug Administration database, $13.1 \%$ involved small bowel perforation, $6.5 \%$ involved aortic perforation, and $4.2 \%$ involved retroperitoneal bleeding. Symptoms such as abdominal and back pain were present in $38.3 \%$ of cases involving IVC penetration. ${ }^{5}$

Therefore, the differential diagnosis for patients with a history of IVC filter placement presenting with these symptoms should address filter complications, including occlusion, incorrect placement, fracture, migration, and penetration of the filter. ${ }^{4}$ If complications occur, treatment options include anticoagulation, endovascular repair, and surgical intervention.

3. White RH, Geraghty EM, Brunson A, et al. High Variation Between Hospitals in Vena Cava Filter Use for Venous Thromboembolism. JAMA Intern Med 2013; 173(7):506512. doi:10.1001/jamainternmed.2013.2352

4. Sella DM, Oldenburg WA. Complications of inferior vena cava filters. Semin Vasc Surg 2013; 26(1):23-28. doi:10.1053/j.semvascsurg.2013.04.005

5. Andreoli JM, Lewandowski RJ, Vogelzang RL, Ryu RK. Comparison of complication rates associated with permanent and retrievable inferior vena cava filters: a review of the MAUDE database. J Vasc Interv Radiol 2014; 25(8):1181-1185. doi:10.1016/j.jvir.2014.04.016

ADDRESS: Vijay Duggirala, MD, Department of Internal Medicine, The Ohio State University Wexner Medical Center, M112 Starling Loving Hall, 320 W. 10th Avenue, Columbus, $\mathrm{OH}$ 43210; vijay.duggirala@osumc.edu

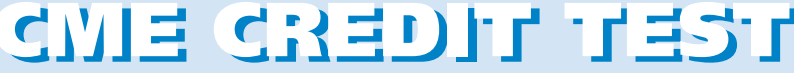 \\ Visit WWW.CCJM.ORG Test your knowledge of clinical topics and earn AMA PRA Category 1 Credit $^{T M}$}

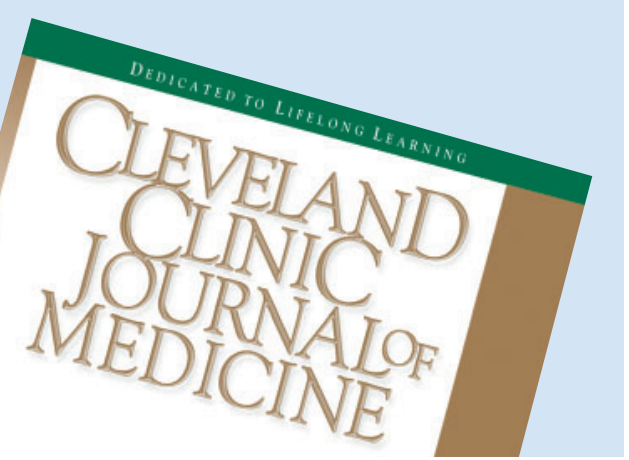

